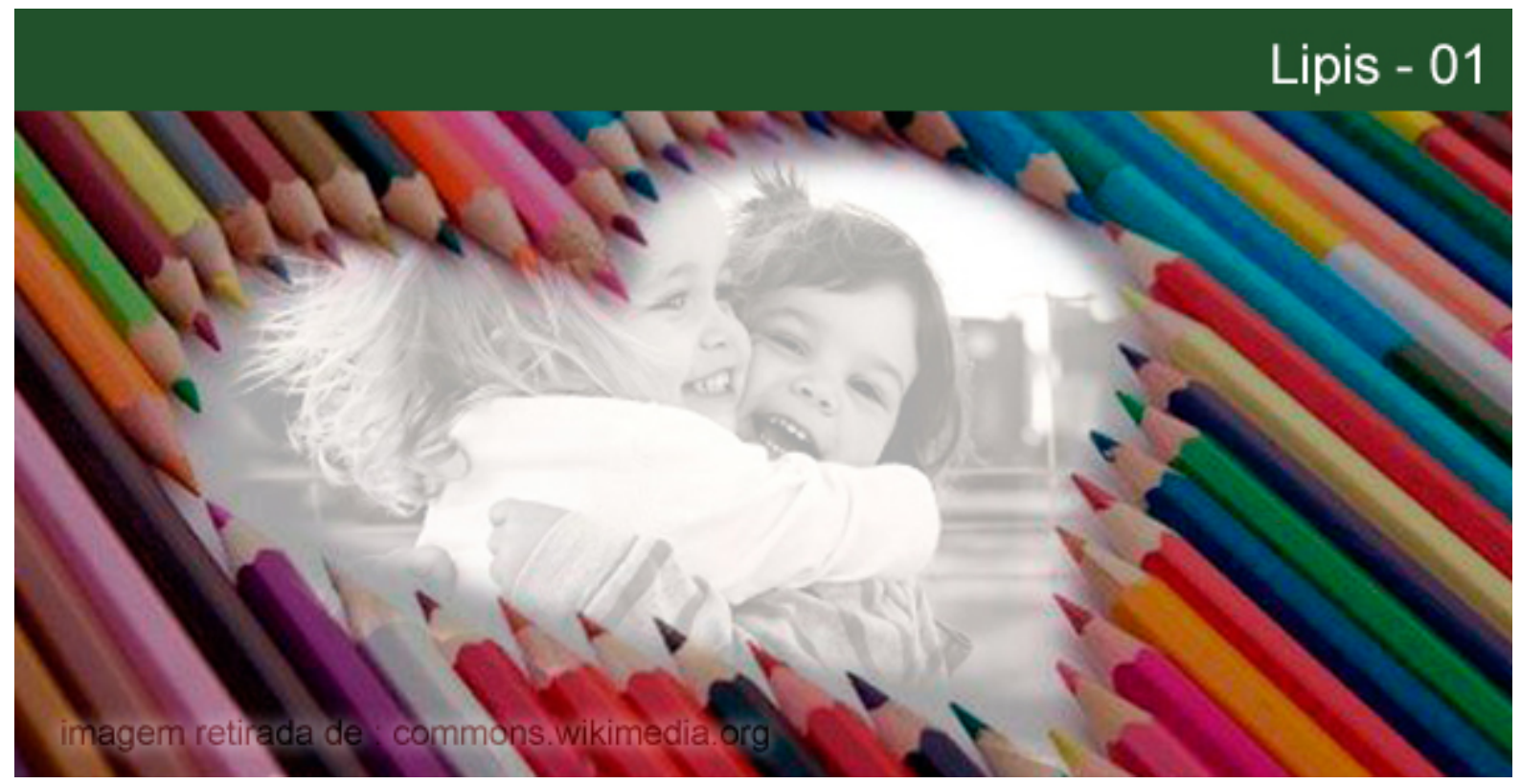

\title{
QUESTÕES CRUCIAIS DA ADOLESCÊNCIA NO CONTEXTO ESCOLAR
}

\section{Betty Bernardo Fuks}

Psicanalista. Dra. em Comunicação e Cultura (ECO/UFRJ). Professora do Programa de Pós-graduação da Universidade Veiga de Almeida (RJ). Bolsista do CNPq. Membro pesquisador da Associação Universitária de Pesquisa em Psicopatologia Fundamental. Pesquisadora. Membro do GT da ANPEPP Psicanálise e Política. Membro do Grupo de Pesquisa Psicanálise e Trabalho (UNB). Editora da Revista on-line Trivium: estudos interdisciplinares. Autora de Freud e a judeidade: a vocação do exílio (Zahar, 2000); Freud e a Cultura (Zahar, 2003); O homem Moisés e o monoteísmo (Civilização Brasileira, 2014).

\section{Izabel Guimarães de Oliveira}

Psicóloga. Especialista em Terapia de Família (ITF/RJ). Mestrado em Psicanálise pela Universidade Veiga de Almeida (RJ). Orientadora Educacional dos Colégios Santo Inácio e São Bento. Atuou como psicóloga no Colégio Pedro II (1988-2015).

Resumo: Este ensaio pretende mostrar alguns impasses da sociedade atual e sua interferência no contexto escolar de adolescentes. Considerando-se a Escola como um espaço onde se fundamentam laços sociais importantes, propomos, tomando como norte o referencial de diferentes campos do saber que se interessam pela articulação entre subjetividade e cultura, refletir sobre uma possível contribuição da Psicanálise ao campo da Educação.

Palavras-chave: Contemporâneo. Comunidade. Adolescente. Sintoma.

\section{TEENAGERS MAJOR SCHOOL ISSUES}

Abstract: This essay aims to show some impasses of today's society and its interference in the school context of adolescents. Considering the school as a place where important social ties are based, we propose, taking as reference the north of different fields of knowledge concerned with the link between subjectivity and culture, reflect on a possible contribution of psychoanalysis to the field of education.

Keywords: Contemporaneity. Community. Adolescent. Symptom.

\section{Nossos tempos e o sofrimento psíquico}

\section{POLÊM!CA $\mid$ LABORE}

Polêmica - Revista Eletrônica da Uerj - Rua São Francisco Xavier, 524, $1^{\circ}$ andar bloco D, sl.1001 • Tels.: +55 21 2334-4088 / 4087 • http://www.e-publicacoes.uerj.br/index.php/polemica/index http://www.labore.uerj.br • laboreuerj@yahoo.com.br 
Já foi dito que a contemporaneidade é um tempo marcado por situações de excesso e de carência. A sociedade do consumo impõe, a todo instante, um novo produto, os gadgets, dispositivos eletrônicos portáteis como celulares, smartphone, leitores de mp3 entre outros, que prometem atender toda e qualquer demanda. Produzidos e ofertados pelo sistema capitalista que se serve tanto do saber científico como das tecnologias em geral para produzí-los, tratam-se de quinquilharias ofertadas ao sujeito que com elas passa a viver uma aparente sensação de saciedade, sem saber o que fazer com a ideia de plenitude, parecendo não conhecer do que se trata desejar. Vivemos sob o lema hedonista de tudo aproveitar sem restrições. A incapacidade atual de se fazer renúncias é enorme e a dificuldade em lidar com frustrações levanta a bandeira do prazer absoluto e incondicional.

O tempo é acelerado, extrapola o mundo do trabalho. As agendas estão lotadas, reinado das urgências. Por outro lado, surgem as construções mais personalizadas do uso do tempo; um poder maior de organização individual da vida. A humanidade luta com seus anseios naturais e suas inerentes limitações e, ao mesmo tempo, procura "burlar” a finitude e a morte, acreditando na ilusão de eterna juventude oferecida pela ciência e novas tecnologias. Em resumo: uma crise de referências repleta de incertezas, expressa na lógica do consumo, do efêmero, do gozo e da artificialidade invade o nosso século. Tudo é temporário, não há perspectiva de permanência e continuidade. Nosso tempo se caracteriza pela falta de raízes e ausência de padrões de comportamentos tradicionais; o que acentua o desiquilíbrio entre segurança e liberdade individual.

Em “Comunidade: a busca por segurança no mundo atual” (2003), Zygmunt Bauman usa como instrumento principal de sua análise o conceito de comunidade para abordar as ambivalências da sociedade em seu estágio atual. A vida em comum, mostra o sociólogo, produz o atrito entre segurança, o que o sujeito precisa para viver tranquilo e confiante, e a liberdade individual. Num comentário sobre o livro de Bauman, Maria Medrado Nascimento (2006), chama atenção para o paradoxo do conceito de “comunidade”: impossibilidade de um equilíbrio entre segurança e liberdade; dependendo da ocasião esses estados se alternam. Alternâncias que tornam a vida em comum um conflito sem fim: segurança sem liberdade significa escravidão dos outros e a liberdade sacrificada em nome da segurança tende a servir à liberdade dos outros. Enfim, não há uma solução perfeita para o dilema na medida em que a cada vez que conseguimos um pouco de segurança, entregamos uma dose de liberdade; a civilização impõe, sempre, uma troca entre eles (BAUMAN, 2003, p. 24).

\section{POLÊM!CA | LABORẸ}

Polêmica - Revista Eletrônica da Uerj - Rua São Francisco Xavier, 524, $1^{\circ}$ andar bloco D, sl.1001 • Tels.: +55 21 2334-4088 / 4087 • http://www.e-publicacoes.uerj.br/index.php/polemica/index http://www.labore.uerj.br • laboreuerj@yahoo.com.br 
Em sua obra, Bauman trata de temas diversos e abrangentes, como globalização, sociedade de consumo, amor, individualidade, e tem como objeto de estudo o cotidiano de pessoas comuns. Enfatizando a ética como a base da sociedade humana, em "Modernidade líquida” (2000), o conceito de liquidez caracteriza o enfraquecimento dos laços sociais na sociedade atual. A modernidade líquida circunscreve uma época de incertezas e insegurança, oposta à modernidade sólida, tempo caracterizado por referenciais morais mais rígidos. A modernidade líquida é a do consumo e do crédito financeiro sem limite, portanto, a da artificialidade, sem perspectiva alguma de permanência e continuidade:

[...] como os líquidos, ela caracteriza-se pela incapacidade de manter a forma. Nossas instituições, quadros de referência, estilos de vida, crenças e conviç̧ões mudam antes que tenham tempo de se solidificar em costumes, hábitos e verdades auto-evidentes (BAUMAN, 2000, p.4).

Ou seja: falta de raízes, ausência de padrões de comportamento tradicionais que se congelam em rotina caracterizam a contemporaneidade. No espaço social, marcado pelo capitalismo moderno, procurou-se substituir o ritmo e a rotina da comunidade por uma outra rotina artificialmente monitorada. Resumindo: o foco do pensamento de Bauman está na tentativa de compreender as consequências desse contexto social atual no processo de subjetivação dos indivíduos, uma vez que o imperativo proposto aos homens é de viver apenas o momento e desconsiderar o futuro.

É possível estabelecer um diálogo entre a ideia do capitalismo como sistema produtor de excesso, fluidez e insegurança (BAUMAN, 2000), e o que a psicanálise tem a dizer sobre o mal-estar contemporâneo. Existe na cultura atual, a cultura comercial de que nos fala Lacan no "Seminário 16", uma proliferação de objetos, os gadgets aos quais nos referimos acima, que interferem nos laços sociais a partir do discurso do capitalista. Não é nossa intenção discorrer sobre o discurso capitalista, aquele que segundo Jacques Lacan, não faz laço social. Apenas gostaríamos de sublinhar, no momento, a indicação lacaniana de que o discurso psicanalítico é a única saída para a impotência do discurso capitalista. Retornaremos mais adiante a esse tema quando tratarmos da conexão Psicanálise e Educação.

Marie-Jean Sauret, em se livro "Psychanalyse et politique: huit questions de la psychanalyse au politique” (2005), enuncia que o capitalismo atual tem como resposta a incidência de sintomas tais como a anorexia, bulimia e toxicomania. Estas patologias que vêm assombrando nossa atualidade, não cessam de nos interrogar sobre particularidades de nossa

\section{POLÊM!CA $\mid$ LABORE}

Polêmica - Revista Eletrônica da Uerj - Rua São Francisco Xavier, 524, $1^{\circ}$ andar bloco D, sl.1001 • Tels.: +55 21 2334-4088 / 4087 • http://www.e-publicacoes.uerj.br/index.php/polemica/index http://www.labore.uerj.br • laboreuerj@yahoo.com.br 
cultura atual. Entretanto é preciso sublinhar que tais sintomas não constituem, a rigor, nenhuma novidade, conforme também quer fazer crer a mídia, na ambição sensacionalista de difundir a existência de uma nova doença. O que há de novo, que seguramente contribui para o aumento de manifestações mórbidas na atualidade, está diretamente ligado ao desenvolvimento maciço do capitalismo na sociedade de consumo. Esta, pari passu com a ciência positivista moderna, promete a recuperação do gozo perdido (SAURET, 2005). Um sintoma como o par anorexia/bulimia não deixa de ser uma oposição à cultura, aliás, como qualquer outro. Ao recusar os inúmeros objetos que o Outro lhe empurra goela abaixo, a anoréxica e a bulímica evidenciam uma desesperada tentativa de manter vivo o desejo (Cf., FUKS \& POLLO, 2010).

O psicanalista italiano Massimo Recalcati também identifica o corpo como o locus do sofrimento na atualidade. Em “A questão preliminar na época do outro que não existe” (2013), ele traz contribuições contundentes ao estudo dos sintomas de maior incidência na contemporaneidade. Para o autor, atualmente o sujeito é convocado a ocupar o lugar de consumidor de acordo com a lei atual do mercado, que não o particulariza. Trata-se de promover o "sujeito-gadget", uma figura produzida pela sociedade de consumo em sua insistência de eliminar de seu caminho os conflitos e fazer com que os sujeitos parasitem em torno de objetos descartáveis. Em base, a teorização lacaniana da sociedade atual como totalmente voltada ao consumo excessivo e ao gozo excessivo, o gozo sem limites (LACAN, 2008), o que traz consequências dramáticas aos processos subjetivos, Recalcati chama atenção para a compulsão ao gozo na atualidade que denunciam os sintomas graves e passagens ao ato.

A ideia de que a sociedade capitalista está concentrada na busca de felicidade e o ideal do excesso, desenvolvida por Bauman (2008), guarda uma afinidade eletiva com a concepção lacaniana de mais-de-gozar que tem como fundamento a busca da felicidade instantânea e completa determinada pelo repúdio à castração simbólica. O abuso de substâncias tóxicas, a compulsão consumista, o excesso de cuidados com o corpo como forma de desmentir a morte e outros sintomas que se apresentam de forma massivamente em nossos tempos, se enquadram perfeitamente na hipótese de um empuxo ao gozo sem limites. De fato, existe algo em comum entre as posições autorais expostas aqui até agora: a tentativa de extinguir o conflito e a falta constitutiva do sujeito dá lugar à fantasia de que é possível eliminar o que atrapalha, o que traz desprazer, enfim, o que incomoda. Assistimos a procura galopante por

\section{POLÊM!CA $\mid$ LABORE}

Polêmica - Revista Eletrônica da Uerj - Rua São Francisco Xavier, 524, $1^{\circ}$ andar bloco D, sl.1001 • Tels.: +55 21 2334-4088/4087 • http://www.e-publicacoes.uerj.br/index.php/polemica/index http://www.labore.uerj.br • laboreuerj@yahoo.com.br 
respostas imediatas e soluções mágicas às questões que emergem na sociedade atual, sempre dentro da lógica de normatização e da adaptação à maioria, quando não por meio de abordagens punitivas sem sentido, como veremos mais adiante.

Entre nós, o psicanalista Joel Birman (2012) formulou a ideia de que a inflação permissiva de excesso pulsional incrementado pelo espaço social encontra-se nos fundamentos do mal-estar contemporâneo. Violência e criminalidade ostensivas são o resultado imediato da carência do uso da função simbólica na atualidade. Sintomas centrados nos registros do corpo e da ação indicam uma ruptura entre os registros do espaço e do tempo, nos quais o espaço assume a forma do somático, materializando-se como volume e profundidade, isto é, perdendo qualquer dimensão significativa. Nessa perspectiva hoje podemos dizer literalmente "que o tempo vai para o espaço na nova cartografia do mal-estar”, (BIRMAN, 2012, p.105), marcada pelo imprevisível e pela instabilidade dos códigos simbólicos estabelecidos. Portanto, com isso, Birman faz valer sua ideia de que mudanças sociológicas experimentadas na pós-modernidade encontram-se na base dos sintomas que mais se manifestam na atualidade.

Observa-se que tanto Sauret como Recalcati e Birman destacam a falência da função paterna, isto é, a diminuição dramática no atual estágio da civilização da interdição do incesto e do assassinato, que tem como consequência imediata o crescimento dramático de patologias ligadas ao corpo, transtornos alimentares e da drogadição e o incremento da violência social. A falta de limites às exigências pulsionais, para esses autores, é o que se encontra na base da falta de simbolização e, consequentemente, do estabelecimento dos laços sociais. Dito de outro modo, na atualidade economia pulsional encontra sérias barreiras à elaboração psíquica o que determina que atuações e passagens, ao ato, perigosas, em função da precariedade dos limites impostos, se consolidam drasticamente na sociedade contemporânea.

Entretanto, o curioso é que encontramos, justamente, num texto de Freud escrito no alvorecer do século XX observações extremamente próximas a que encontramos no pensamento desses autores. Em “A Moral Sexual Civilizada e Doença Nervosa Moderna” (1908), Freud denuncia que o adoecimento da população estaria relacionado ao progresso tecnológico e as grandes descobertas dos “tempos modernos” (p.189).

Cresceram as exigências impostas à eficiência do individuo e só reunindo todos os seus poderes mentais ele pode atendê-las. Simultaneamente, em todas as classes aumentam as necessidades individuais e a ânsia de prazeres materiais; um luxo sem

\section{POLÊM!CA $\mid$ LABORE}

Polêmica - Revista Eletrônica da Uerj - Rua São Francisco Xavier, 524, $1^{\circ}$ andar bloco D, sl.1001 • Tels.: +55 21 2334-4088 / 4087 • http://www.e-publicacoes.uerj.br/index.php/polemica/index http://www.labore.uerj.br • laboreuerj@yahoo.com.br 
precedentes atingiu camadas da população a que ate então era totalmente estranho; a irreligiosidade, o descontentamento e a cobiça intensificam-se em amplas esferas sociais. O incremento das comunicações resultante da rede telegráfica e telefônica que envolve o mundo alteraram completamente as condições do comercio. Tudo é pressa e agitação [...] A vida urbana torna-se cada vez mais sofisticada e intranquila. Os nervos exaustos buscam refugio em maiores estímulos e em prazeres intensos [...] A literatura moderna se ocupa de questões controvertidas que despertam, [...] o desprezo por todos os princípios éticos e por todos os ideais. (FREUD, 1908, vol. IX, p.189).

Portanto, a preocupação para com as transformações na tecnologia, as exigências performáticas, o consumo, a valorização da ética e dos ideais, que afetam a sociedade contemporânea, são muito semelhantes a de Freud. Será que tudo mudou de lá para cá? Nossa hipermodernidade, usando aqui o termo de Gilles Lipovetsky (2000) para destacar o momento atual de nossa sociedade, tempo da cultura de excesso, do sempre mais se encontra tão distante assim da modernidade vienense? Ou o sujeito hipermoderno de Lipovetsky apenas exacerba, mais do que qualquer outro, a ilusão de liberdade, ultrapassando com maior facilidade os limites que mantém os laços sociais?

De todas as formas, eis o cenário que nos é apresentado hoje: uma sociedade baseada no excesso da informação e no estímulo das necessidades em detrimento do desejo. Rapidez das transformações sociais, da expansão das mídias, das novas tecnologias e configurações familiares inauguram outras formas de experimentar esse momento aumentando ou diminuindo os limites da segurança e da liberdade subjetiva que dão suporte à vida em comum.

\section{Adolescência e o mal-estar na cultura}

Passemos, então, à intenção primordial desse artigo que é a de pensar a contribuição possível da Psicanálise ao campo da Educação, em função das transformações sociais e econômicas contemporâneas que atingem os adolescentes e suas demandas ao sistema escolar. O incremento vertiginoso do mal-estar contemporâneo social e psíquico, sem dúvida, encontra-se disseminado em qualquer faixa etária e classe social; e sendo a angústia o afeto que emerge nessa situação, atingindo os processos subjetivos, acontece de Psicanálise ser convocada, cada vez mais, a estabelecer relações com outros campos do saber.

De uma maneira geral, a adolescência é um período turbulento, marcado pelo processo de luto e escolhas próprias. O luto se caracteriza pela perda de um elo significativo entre o sujeito e o objeto (FREUD, 1917). Freud circunscreveu o espaço da fusão originária entre a

\section{POLÊM!CA $\mid$ LABORE}

Polêmica - Revista Eletrônica da Uerj - Rua São Francisco Xavier, 524, $1^{\circ}$ andar bloco D, sl.1001 • Tels.: +55 21 2334-4088 / 4087 • http://www.e-publicacoes.uerj.br/index.php/polemica/index http://www.labore.uerj.br • laboreuerj@yahoo.com.br 
criança e a mãe, lugar da completude imaginária. A sociabilidade tem início exatamente quando da primeira perda, isto é, quando a criança separada minimamente do reino materno se vê diante do vazio a partir do qual manterá a distância entre ela e o objeto do desejo. O vazio institui a linguagem com a qual a criança começa a elaboração de um luto que permite dar sentido a essa perda originária e fazer suas escolhas. Esse momento lógico da constituição do sujeito encontra-se sob o signo da repetição em outros momentos da vida do ser humano. Ou seja, para que o adolescente se constitua como sujeito e faça suas próprias escolhas é preciso que haja um trabalho de separação dos pais com quem conviveu na infância.

O filme "Divertidamente" de Peter Hans Docter, diz de forma poética sobre esse luto da adolescência. Uma menina de 11 anos vive uma experiência de perda. Seu pai recebe uma oferta de trabalho que obriga toda a família a se mudar para milhares de quilômetros do lugar onde cresceu, onde tem seus amigos e tudo o que ama. O enredo da película deixa à vista não apenas as dificuldades do processo de elaboração da jovem menina de sua cidade, de seus amigos que lá ficaram e da separação dos próprios pais, como também a problemática dos adultos em aceitar o luto dos adolescentes pelas perdas inerentes à própria vida. Baseado na própria experiência de sua filha adolescente, o diretor da Pixar comove plateias ao resgatar a função do luto no plano individual e coletivo.

Quanto à possibilidade do sujeito adolescente efetuar suas próprias escolhas, é preciso observar que não há escolha que prescinda de indicativos, direções, determinantes que lhe são anteriores (ALBERTI, 2004). O sujeito ao longo de sua infância recebe de seus pais, educadores, colegas, meios de comunicação, enfim, do mundo à sua volta, o que lhe é transmitido pela linguagem falada, escrita, visual, comunicativa e mesmo pelo silêncio. Os processos de identificações são permanentes e nada impede que tanto na adolescência, como em qualquer época da vida, o sujeito continue se identificando com o que o Outro lhe transmite. É certo que muitas vezes, diante de tantas reações adversas por parte dos filhos, durante a travessia da adolescência, os pais desistem de desempenhar sua função, entendem que não são mais ouvidos, levados a sério, respeitados, e então, desistem. Neste caso, são os pais que se afastam antes dos seus filhos poderem se separar deles, invertendo os papéis, de forma que a única solução encontrada pelo adolescente nesse momento em que se vê abandonado é a de lutar desesperadamente por atenção. Começa então uma série infinita de dificuldades e problemas da adolescência, que será tanto maior quanto menor tiverem sido justamente as referências primárias imprescindíveis para o exercício das escolhas. Do ponto

\section{POLÊM!CA $\mid$ LABORE}

Polêmica - Revista Eletrônica da Uerj - Rua São Francisco Xavier, 524, $1^{\circ}$ andar bloco D, sl.1001 • Tels.: +55 21 2334-4088 / 4087 • http://www.e-publicacoes.uerj.br/index.php/polemica/index http://www.labore.uerj.br • laboreuerj@yahoo.com.br 
de vista da psicanálise é a singularidade da história de cada sujeito que revelará, a posteriori, os impasses de sua adolescência (ALBERTI, 2004). As travessias são tumultuadas, mas o sujeito normalmente completa seu trajeto, modificado; desde que lhe seja dado o direito de vivê-la subjetivamente, isto é, elaborando a história que o determina.

No que tange às múltiplas relações entre as patologias e as mudanças contemporâneas, segundo alguns psicanalistas, a marca da atual geração de jovens é a alternância entre a apatia e o excesso pulsional. João Batista Ferreira (2004) é um dos que defendem esta ideia: na atualidade o adolescente oscila entre se apagar ou incendiar-se, como denúncia, talvez, de sua falta de esperança no mundo, ou procura desesperada por encontrar o seu lugar. Desde cedo, escreve o psicanalista, a criança acredita ser "um convidado ao alegre e divertido banquete da vida”. Mais tarde, ela deverá sair da proteção dos pais para ganhar o mundo, sabendo que sendo obediente, em breve chegará sua hora. A criança captura a promessa, recolhe-se na latência e uma vez adolescente procura pela "festa prometida”. Entretanto, nesse trajeto restalhe ficar aprisionado na apatia, pois para o autor, esta geração parece não ter o que inovar, o que romper, e tampouco tabus para quebrar. Outra alternativa seria optar pelo excesso, trazendo um discurso emoldurado com o uso de drogas ou abuso de álcool, a prática indiscriminada de sexo, deboche sobre conceitos como respeito, admiração e compromisso.

Muitas vezes, jovens adolescentes denunciam o mal-estar contemporâneo de forma bastante trágica. A dependência extrema das drogas ou qualquer outra compulsão à repetição sintomática que pode levar à morte revela a dificuldade da separação dos pais que os protegeram sem apresentá-los às frustrações, às decepções e às impossibilidades que a vida impõe. Não aprenderam a reagir diante de um não, diante da dor, da falta e da diferença. Nesses casos, a falência da função paterna é responsável pela falta de base e de estrutura para que o sujeito adolescente enfrente as diversidades ao longo de sua trajetória. Freud já denunciara em “O mal-estar na civilização” que essa situação ocorre como se os jovens fossem enviados para o polo norte com roupas de banho e com os mapas dos lagos italianos (FREUD, 1930/1974, p. 158). Os adolescentes se percebem despreparados e através de seus sintomas pedem ajuda para aceitar a falta, fazer renúncias, ter tolerância e alcançar a satisfação.

Por outro lado, é possível identificar na adolescência uma capacidade imensa de reivindicar mudanças sociais, talvez porque seja um período, por excelência, das primeiras formações comunitárias. O grupo funciona para o adolescente como garantia de

\section{POLÊM!CA $\mid$ LABORE}

Polêmica - Revista Eletrônica da Uerj - Rua São Francisco Xavier, 524, $1^{\circ}$ andar bloco D, sl.1001 • Tels.: +55 21 2334-4088 / 4087 • http://www.e-publicacoes.uerj.br/index.php/polemica/index http://www.labore.uerj.br • laboreuerj@yahoo.com.br 
reconhecimento de novos traços identificatórios. O sujeito adolescente, em seu processo de vir a ser, encontra em seus pares a tentativa de sentir-se assegurado e ao mesmo tempo conquistar sua liberdade. As moções de liberdade legitimada pelo grupo, escreve Maria Rita Kehl, enfraquecem as identificações com a palavra paterna da infância (KEHL, 2000b, p. 41). É nesse momento que alguns grupos de adolescente têm uma experiência marginal para forçar uma inscrição na cultura; o que não quer dizer, segundo a autora, que sejam marginais ou perversos. Para a autora, durante o processo de desidealização e separação das figuras parentais uma comunidade de jovens pode vir dar suporte à re-escrita da fundação da cultura: o fim do poder arbitrário e união dos irmãos em torno do vazio constitutivo da cultura. Assim, na microcomunidade de adolescentes a experiência é inteiramente diferente, por exemplo, de outras comunidades que não arriscam mudanças subjetivas em nome de segurança e do status quo. Não sem razão, são os jovens que muitas vezes encabeçam lutas coletivas por mudanças sociais, e construção de novos laços sociais.

Sabemos que a Psicanálise é uma prática clínica que exige do analista a posição de crítico da cultura que testemunha. No campo do atendimento psicossocial o psicanalista é convocado, cada vez mais, a trabalhar com situações que excedem os enquadramentos psicopatológicos. Estamos nos referindo aqui à problemática dos jovens adolescentes de comunidades pobres ligados ao tráfico de drogas. Num artigo cujo título por si só é bastante sugestivo - "Para uma clínica do uso de álcool e drogas com adolescentes das comunidades do Rio de Janeiro” - o psicanalista Francisco Fernandes, com muita acuidade e sensibilidade, mostra que a questão dos jovens envolvidos com o tráfico de drogas diz respeito muito mais à "uma prática que se propagou a partir de mecanismos culturais que, nos últimos 40 anos, agiram nas fraturas das dinâmicas institucionais encarregadas de propor e zelar pela ordem” (FERNANDES, 2014, p. 41) do que os quadros psicopatológicos. As consequências desse processo na adolescência são, em sua maioria, da ordem da tragédia. Desde muito cedo esses jovens vivem o fracasso da função paterna não apenas nas casas de seus pais, igualmente vítimas das mesmas fraturas, como nas instituições escolares e socioeducativas de onde, em geral, são expulsos por conta de atitudes agressivas exacerbadas para com seus colegas e educadores. Diante desse real nada lhes resta além de se tornarem delinquentes à espera de uma morte prematura, antes mesmo de chegar à idade adulta. Mas antes disso, o sofrimento psíquico ao qual serão submetidos em instituições socioeducativas, onde em geral suportam

\section{POLÊM!CA $\mid$ LABORE}


toda sorte de maldades, impede todo e qualquer esforço de levá-los à assumir a responsabilidade pelos atos infratores e criminosos que cometeram.

Essa realidade patética continua sendo, sistematicamente, ignorada por muitos. Refirome aqui aos que idealizaram o Projeto de Emenda Constitucional (PEC) 171/93 que reduz a maioridade penal para 16 anos. O objetivo, quase que imperceptível, é, em si mesmo, uma repetição traumática: apagar as marcas de um crime, a violência contra adolescentes da periferia, negros em sua maioria. Esta é a conclusão que chegamos ao final do artigo "Para Brasília só com passaporte” de Eliana Brum. Baseada nos dados do Fundo das Nações Unidas para a Infância, a jornalista conclui que se dos 21 milhões de adolescentes brasileiros, apenas 0,013\% cometeram atos contra a vida, e se os assassinatos de jovens brancos diminuíram enquanto os dos jovens negros cresceram, então a vida de um adolescente negro não merece ser vivida. Não se trata de escravizar como aconteceu até o século XIX, mas da tentativa de exterminá-los. São poucos os esforços públicos na educação e saúde para evitar que os jovens se tornem delinquentes e caiam na marginalidade, enquanto que o projeto de lei de confiná-los em prisões superlotadas significa uma sentença de morte.

Na atualidade são inúmeras as indagações que surgem nas escolas, em relação ao que vivem os adolescentes, independente da faixa social a qual pertencem. O nível dos impasses, incidência de sintomas por vezes mortíferos causados pelo empuxo ao gozo, exigem dos educadores um reposicionamento de todos no sentido de incluir os limites e fortalecer o laço social enquanto endereçamento ao outro e ao Outro. A Escola é um espaço fundamental à transmissão psíquica da lei pela qual o jovem possa se engajar em algum ideal e operar transformações como o verdadeiro protagonista do encontro com seu desejo. É sob o pano de fundo, o da doação, que entendemos a aproximação entre Psicanálise e Educação estabelecida por Freud, ao caracterizá-las como profissões impossíveis. E o que isso quer dizer? No sentido lógico, são práxis que trabalham com o limite da linguagem, portanto estão mais preparadas para acolher o estranho. Mas se qualquer homologia implica diferenças, há que se considerar a função de cada uma dessas disciplinas para enfrentar os desafios colocados pela sociedade contemporânea.

Do ponto de vista das fronteiras entre o campo da Psicanálise e o da Educação, o analista deve cooperar na execução do trabalho do educador, mas jamais ocupar o seu lugar, adverte Jeanne D’Arc Carvalho (2012), num artigo contundente sobre o diálogo entre o psicanalista e o educador. Trata-se, então, de refletir sobre a orientação do psicanalista a

\section{POLÊM!CA $\mid$ LABORE}

Polêmica - Revista Eletrônica da Uerj - Rua São Francisco Xavier, 524, $1^{\circ}$ andar bloco D, sl.1001 • Tels.: +55 21 2334-4088 / 4087 • http://www.e-publicacoes.uerj.br/index.php/polemica/index http://www.labore.uerj.br • laboreuerj@yahoo.com.br 
propósito das dificuldades que o educador enfrenta, no exercício de sua profissão, com alunos que atravessam o turbilhão da adolescência somado às características de uma sociedade com poucas referências à lei e extremamente tumultuada. Para Carvalho, o desafio atual dos educadores reafirma a pergunta fundamental da psicanálise: “O que é um Pai”? Desafio que implica o educador na tarefa de incluir em seus cálculos de trabalho a ausência de autoridade nas famílias de crianças e jovens adolescentes, ou seja, a falta de transmissão da lei simbólica capaz de gerar o desejo. Diante disso, há que ressaltar que o professor, no exercício de sua prática, deve se posicionar enquanto sujeito comprometido e responsável pela transmissão da lei, o que difere do ato puro e simples de educar. Lembremos que Freud, em seu prefácio ao livro “A juventude desorientada”, escrito pelo professor August Aichhrorn, fez a sugestão de que o educador pudesse se submeter à experiência analítica para tratar dos jovens abandonados, isto é, dos jovens que por carência de função simbólica, não encontraram outra saída do que deliquar.

A presença do discurso psicanalítico nas questões ligadas ao campo da educação, especialmente nesses tempos em que o discurso capitalista, por meio de comunicação de massas, impede a emergência do sujeito é crucial. E, na medida em que o psicanalista trabalha com o sujeito dividido, em contraposição ao sujeito sem falta, ele se pronuncia a favor de um sistema escolar que ofereça mais espaço de escuta, oportunize ambientes favoráveis ao debate, proporcione ao jovem momentos de discussão e incentive a produção da palavra como ponto de partida para a transformação. A escola tem um papel fundamental de se oferecer como suporte para que o jovem possa se desenvolver e trilhar um caminho de elaborações, frustrações e renúncias, reconhecendo a lei em qualquer situação experimentada ao longo da vida.

Recordemos que em "Estudos sobre a Histeria”, Freud relata uma interpelação de um de seus pacientes - “Como o senhor se propõe ajudar-me?” - para em seguida oferecer uma resposta ética ao leitor:

Você poderá convencer-se de que ganharemos muito se conseguirmos transformar seu sofrimento histérico em infelicidade comum. Com uma vida mental que foi restaurada, transformando-se em saúde, você ficará melhor armado contra essa infelicidade (FREUD, 1895, p. 363).

Se nos basearmos nesse argumento freudiano de que o sintoma é sem dúvida uma tentativa do sujeito se posicionar frente ao mal-estar, então devemos reconhecer que a

\section{POLÊM!CA $\mid$ LABORE}

Polêmica - Revista Eletrônica da Uerj - Rua São Francisco Xavier, 524, $1^{\circ}$ andar bloco D, sl.1001 • Tels.: +55 21 2334-4088 / 4087 • http://www.e-publicacoes.uerj.br/index.php/polemica/index http://www.labore.uerj.br • laboreuerj@yahoo.com.br 
Psicanálise se insere numa nova epistemologia para a qual sendo a falta inevitável, o menor dano é restaurar o psiquismo para que o sujeito esteja minimamente preparado para aceitar as perdas. Assim, toda a reflexão sobre a adolescência que esteja apoiada nos impasses culturais que atravessamos permite o psicanalista reafirmar que a escola precisa exercer a função de fornecer ao sujeito-aluno base e alicerce, para que ele possa estar mais preparado às adversidades, que certamente encontrará ao longo se sua caminhada e se comprometer com a transmissão da lei às gerações de adolescentes que virão.

\section{Referências}

ALBERTI, S. O Adolescente e o Outro. Rio de Janeiro: Jorge Zahar Editor, 2004.

BAUMAN, Z. O Mal Estar da Pós-Modernidade. Rio de Janeiro: Jorge Zahar Editor, 1997.

Comunidade: A busca por segurança no mundo atual. Rio de Janeiro: Jorge Zahar Editor, 2003.

Modernidade Líquida. Rio de Janeiro: Jorge Zahar Editor, 2000.

BIRMAN, J. Mal-estar na Atualidade: A Psicanálise e as Novas Formas de Subjetivação. Rio de Janeiro: Civilização Brasileira, 2007.

O Sujeito na Contemporaneidade. Rio de Janeiro: Civilização Brasileira, 2012.

BERNAUT , I. L’adolescent et le séparation. Paris: PUF, 2010.

CARVALHO, J.D. Psicanálise e Educação: um diálogo sobre o estranho e a inclusão. Revista de Psicologia Plural. B. Horizonte, n. 35, jan/junho, 2012. p. 47-58.

FERNANDES, F.L. Para uma clínica do uso de álcool e drogas com adolescentes das comunidades do Rio de Janeiro. Ágora: Estudos em teoria psicanalítica. Rio de Janeiro: Contra-capa Livraria, 2014, p. 39-40.

FERREIRA, J.B. Adolescência. Cadernos de Psicanálise. Círculo Psicanalítico do Rio de Janeiro, ano 26, n.17,2004, p.213-227.

FREUD, S. (1895 [1893]). Estudos sobre a Histeria. Rio de Janeiro: Imago, 1974. (Edição Standard Brasileira das Obras Psicológicas Completas de Sigmund Freud, v.2).

(1908 [1907]). Moral sexual “civilizada” e doença nervosa moderna. Rio de Janeiro: Imago, 1974 Rio de Janeiro: Imago, 1974. Edição Standard Brasileira das Obras Psicológicas Completas de Sigmund Freud, v.21.

(1930 [1929]). O mal-estar na civilização. Rio de Janeiro: Imago, 1974. Edição Standard Brasileira das Obras Psicológicas Completas de Sigmund Freud, v.21.

(1917 [1915]). Luto e Melancolia. Rio de Janeiro: Imago, 1974. Edição Standard Brasileira das Obras Psicológicas Completas de Sigmund Freud, v.14.

(1925 [1923]). Prefácio a Juventude Desorientada. Rio de Janeiro: Imago, 1974. Edição Standard Brasileira das Obras Psicológicas Completas de Sigmund Freud, v.12.

\section{POLÊM!CA $\mid$ LABORE}

Polêmica - Revista Eletrônica da Uerj - Rua São Francisco Xavier, 524, $1^{\circ}$ andar bloco D, sl.1001 • Tels.: +55 21 2334-4088/4087 • http://www.e-publicacoes.uerj.br/index.php/polemica/index http://www.labore.uerj.br • laboreuerj@yahoo.com.br 
FUKS, Betty B. \& POLLO, Vera. Estudos psicanalíticos sobre anorexia: quando se come "nada", Revista Latinoamericana. Psicopatolologia. Fundamental. São Paulo, vol.13, n. 3, set/2010. p. 412-424.

KEHL, M. R. Existe uma função fraterna? In: KEHL, M. R. (Org.). Função fraterna. Rio de Janeiro: Relume Dumará, 2000a. p. 31-47.

LACAN, J. (1968-69). O Seminário: Livro 16, de um Outro ao outro. Rio de Janeiro: Jorge Zahar Editor, 2008. (1969-70). O Seminário, O avesso da Psicanálise: Livro 17. Rio de Janeiro: Jorge Zahar Editor, 1992.

LIPOVETSKY, G.; SÉBASTIEN, C. Os tempos Hipermodernos. São Paulo: Barcarolla, 2004. 2005.

A Era do Vazio: ensaios sobre o individualismo contemporâneo. São Paulo, Bauru: Ed. Manole,

NASCIMENTO, M. M. Entre Segurança e Liberdade: desafios da comunidade na contemporaneidade.

Sociedade e Estado, vol. 21, n. 2, p. 561-567. Maio/agosto, 2006.

RECALCATI, M. A questão preliminar na época do Outro que não existe. Latusa Digital, n.7, ano 1, jun/2004. Disponível em: <http://www.latusa.com.br/pdf_latusa_digital_7_a2.pdf > . Acesso em: set. 2013.

SAURET, M-J. Psychanalyse et politique: huit questions de la psychanalyse au politique. Toulouse: Presses Universitaires Mirail, 2005.

Recebido em: 14/02/2015.

Aceito em: 21/03/2016.

\section{POLÊM!CA $\mid$ LABORE}

